Portland State University

PDXScholar

7-23-2020

\title{
So Many Choices: an Experimental Study of Digital Television Choice, Customization, and Satisfaction
}

Johanna Lee Hoener

Portland State University

Follow this and additional works at: https://pdxscholar.library.pdx.edu/open_access_etds

Part of the Communication Commons

Let us know how access to this document benefits you.

\section{Recommended Citation}

Hoener, Johanna Lee, "So Many Choices: an Experimental Study of Digital Television Choice, Customization, and Satisfaction" (2020). Dissertations and Theses. Paper 5538.

https://doi.org/10.15760/etd.7412

This Thesis is brought to you for free and open access. It has been accepted for inclusion in Dissertations and Theses by an authorized administrator of PDXScholar. Please contact us if we can make this document more accessible: pdxscholar@pdx.edu. 
So Many Choices:

An Experimental Study of Digital Television Choice, Customization, and Satisfaction

by

Johanna Lee Hoener

A thesis submitted in partial fulfillment of the requirements for the degree of

Master of Science

in

Communication

Thesis Committee:

Lee Shaker, Chair

Jefferey Robinson

Cynthia-Lou Coleman

Portland State University

2020 


\begin{abstract}
Internet streaming television is increasingly available in society and is changing the way television is viewed by creating more and more choices for consumers. We no longer watch the same three channels on television, now the consumer controls when, where, and what to watch. Producers of this digital media landscape provide customization mechanisms that consumers also engage in, creating tailored presentations of content.

This study seeks to understand what the large landscape of choice does to our satisfaction in viewing choice and what part customization plays in that satisfaction through an experimental-survey design. Drawing from choice literature which points in the direction of satisfaction being lowered when consumers are faced with too many choices, and customization literature from marketing research and business studies, the researchers test 2 hypotheses relating to high choice and low choice groups and customized and non-customized groups and participants subsequent satisfaction.

Findings suggest that participants in a high choice and customized environment are more satisfied with their viewing choice, which contradicts much of the choice literature. When it comes to digital media consumers want many choices.
\end{abstract}




\section{Acknowledgements}

I would like to thank my family for their patience and support throughout the process of earning this degree. Credit for completing this project must be extended especially to my husband for always believing that I could accomplish my goals.

A huge thank you to Dr. Lee Shaker for all his support and guidance in the long journey of this master's thesis. My committee, Dr. Jeffrey Robinson and Dr. Cynthia-Lou Coleman gave support and excellent editorial advice to make this possible. Thank you to all my friends and colleagues for always encouraging me and for their readiness to read yet another draft of this document. 


\section{Table of Contents}

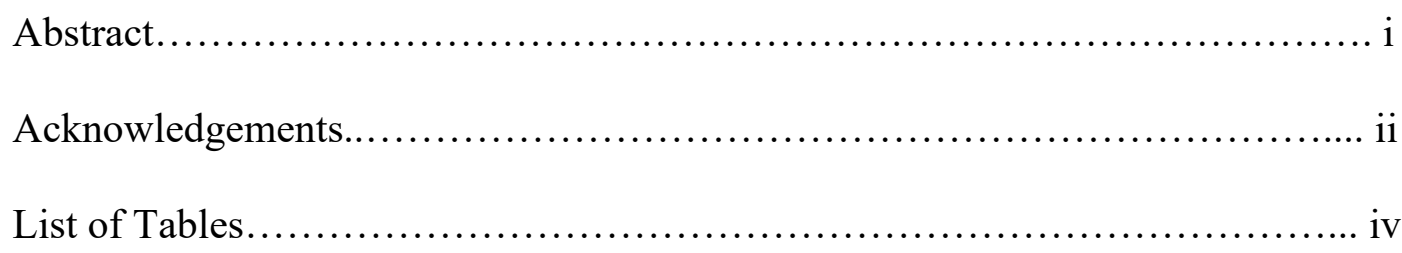

Introduction......................................................... 1

Review of Literature...................................................... 3

Data and Methods................................................... 22

Results............................................................ 28

Discussion......................................................... 30

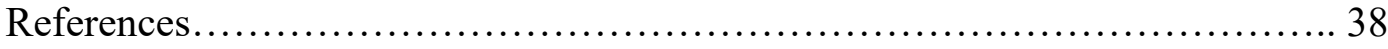

Appendix A. Survey................................................ 44

Appendix B. List of Top Television Shows............................. 47 
List of Tables

Table 1. Sample Demographics......................................... 23

Table 2. Viewer Satisfaction.......................................... 28 


\section{Introduction}

Television that is accessed through Internet streaming outlets is more than a fad. Specific and current outlets such as Hulu, Netflix, YouTube, and Amazon Prime may come and go, but the services they provide are here to stay in some form or another (Christian, 2012, Chamberlain, 2010, Simon \& Rose, 2010). What these outlets have in common is that they bring television and information to an individual's finger tips in an instant. They are breaking down former television norms, much like cable television did in the past. Increasingly, the audience decides when, where, how, and what to watch. These outlets are simplifying the process of information and entertainment delivery, but at the same time force individuals to make decisions on their own about what media to consume (Duffy \& Thorson, 2009). The days of group watching a favorite television show every Sunday night at the same time are slipping away and being replaced with individuals scrolling through options and customizing their own program schedule (Gitlin, 2000).

Television accessed on the Internet changes how audiences consume media. With the number of choices and opportunities for methods of viewing personally customizable content, the audience is faced with the possibility of choice overload. This may have an impact on viewers' experiences and their satisfaction in watching television. As entertainment and information are pursuits that take up a majority of leisure time in Western culture, this is an important area of research. If we spend our time seeking fulfillment in media, it is justified that we understand what makes us satisfied and what lessens our satisfaction. Thus, the guiding research question explored in this study is: 
How do choice and customization relate to people's satisfaction when viewing television?

The following thesis findings explore television, choice, satisfaction, and customization. Drawing from psychology, business studies, and other areas of social research, this study finds that people given more choices in Internet television report higher satisfaction. Also, when an individual believes that the television choices in front of them were customized for them, they are more satisfied. The study that follows explores this issue through survey experimental design. 


\section{Television}

Television is a large part of American culture. In 2018 the Bureau of Labor Statistics reported that people ages 15 and older spend 2.8 hours watching television a day, with overall leisure time clocking in at 5 hours a day (www.bls.gov). What this statistic does not capture is the infiltration of Internet access to television, which rearranges the viewing habits of audiences from a schedule-based single source of visual information to "user-generated video, online platforms, and personalized interfaces," (Simon \& Rose, 2010, p. 52). Thus, Internet is important here because it allows more viewing choices for the audience.

Recent interest in the trend of viewer-controlled content traces back to the advent of TiVo and the subsequent introduction of other Digital Video Recording devices (DVRs). This technological advance allowed audiences to record television shows and watch them at their leisure while also skipping commercials. DVRs also changed the reliance of audiences on traditional scheduling, which sparked an upheaval in television production (Chamberlain, 2010, Carlson, 2006). "Prior to the introduction of and expansion of digital cable, satellite television, DVRs, and broadband Internet, selecting what to watch was as simple as glancing at a grid of local listings or spending a moment flipping stations," (Chamberlain, 2010, p. 85). Viewing today takes place in an entertainment and information landscape that offers both the freedom to choose what to watch and when, but also ensures that viewers must make more decisions about viewing television. This shift in television also changes how we should conceptualize television from, "an interrelated system in which content is financed, produced, packaged, 
distributed, screened and engaged," (Chamberlain, 2010, p. 85), to one that is an individual experience on the part of a viewer with access to more outlets and content that is found in many places.

"Television is truly a medium in transition: neither analog nor digital, it occupies an indeterminate place somewhere between two technological regimes," (Dawson, 2010, p. 96). The Internet has changed how people receive information as well as how they make choices, "once messages are digitized, manipulation of media becomes infinite, allowing the individual much more control than traditional means," (Ruggiero, 2000, p. 16). This ability to customize or control elements of information leads to complications for making decisions and the way we view media. Indeed, "if digitalization and convergence do not make obsolete television sets, they would appear to make obsolete television viewers," (Dawson, 2010, p. 98). While "obsolete" may be harsh, what Dawson has hit on is that the way of watching television up to the point in time that Internet access has become more widely available has changed how a viewer watches the content. While this line of thinking relates to the power of the producers of television technology, content, and the organization of personally tailored messages, audience members are also implicated. They are faced with the difficulty of having many outlets to choose from (Dawson, 2010). Viewing is increasingly an act affected by choice, satisfaction in choices and customization, "television interfaces have become gateways to the content we desire, enabling individualized viewing patterns and subtly reformatting our televisual experiences along vectors of customization and control," (Chamberlain, 2010, p. 85). 
Through this gateway consumers must navigate the massive amount of choice in digital media.

\section{Choice}

How do we make choices, and what are the factors that seem to sway a decision process? Schwartz (2009) puts forward two "self-evident" truths about people that while are intuitively true, have been widely disputed through research:

1. People need motivation to get them to act. If they already have one motiveone reason - to do something, and you give them a second reason to do that thing, their motivation to act will increase.

2. The more freedom people have, the better off they are. The more choice people have, the more freedom they have, therefore, the more choice people have the better off they are. (pp. 391-392)

These truths are easily agreed with on the surface, but mounting evidence of how people actually make choices leads to the conclusion that more choice is not better and may lead to a lack of motivation to choose. Being aware of this 'common knowledge' attitude toward choice allows us to understand both people's actions and the media landscape in which we find ourselves. If we believe that more choice is better, it is a logical step that cable television providers and vendors on other media platforms will increasingly offer more selection. The real truth of the matter is that, even with nearly unlimited television outlets, we still complain, “there's nothing on." This "“choice overload' can lead to paralysis, poor decisions, and dissatisfaction with even good choices," (Schwartz, 2009, p. 392). Thus, looking at the process of choosing in general will shed light on how people make choices in their media options. 
One explanation of how choices are made involves the exploration of a reasonbased process (Tversky \& Kahneman, 1981) that proceeds from an assumption that people use reason to make decisions. This method of looking at choice takes a practical application view by assessing conflicts between choices and an individual's ability to reason or think through the attractiveness of one option over the other (Shafir, Simonson, \& Tversky, 1993). Some models look at choice as a more logical formula, with known inputs and outputs that culminate with a decision (Khan \& Lehmann, 1991; Tversky \& Kahneman, 1981). This approach posits that choice is a systematic process. Given the large amount of media choice, each decision is impacted by many elements that contribute to making one choice over another. Some of these elements include number of choices, variety of choice, and personal preference.

Kahn and Lehmann (1991) conducted an experiment looking at uncertainty in choice and personal preference in an attempt to explain the decision process by looking at different types or features of choices. Using vending machine snack items as the stimulus for the study, they found that the number of items to choose from, the variety of items, and the number presented in the assortment all had an impact on the decision process. These factors showed that "consumers look at assortment as more than just an offering of their most preferred item... consumers evaluate assortments in terms of their flexibility for future choice and the effort to weed out the unacceptable alternative," (p. 296-297). This suggests that people not only look at number of items but also at the difficulty of deciding between preferred items, which takes the reason-based model further. It also suggests that people will attempt to think ahead by choosing one thing 
over another. This also explores the decision process in an environment with many options, similar to the media landscape.

Wilson, Lisle, Schooler, Hodges, Klaaren, and LaFleur (1993) found that when people are asked to think explicitly about a particular decision their satisfaction is lessened, "people may not be aware of how they are weighing the information, but they often use schemes that are adaptive and functional," (p. 332). In their study, Wilson et al. (1993) asked participants to verbalize why they liked or disliked a particular art poster. Those who did this were less satisfied with their choice. These implications point to both the 'behind the scenes thought processes' that occur and the difficulty in measuring satisfaction in choice. If asking someone why they like a particular item decreases the satisfaction, researchers must approach satisfaction in choice measures carefully.

It is possible to have too many choices but finding the threshold for a definitive number of choices varies by context. Iyengar, Jiang, and Huberman (2003) explored this in a study concerning employees and their 401(K) investment plans. Their findings suggest that when employees have two choices in funds to invest in, participation goes up to 75 percent compared to employees with 59 choices in funds to invest in, which showed 60 percent participation in financial planning. This study suggests that 'too much' choice overrides or lessens the ability to choose. This may also occur in the area of media and entertainment; the more choices we are asked to make by media providers, the less able we will be to make a choice.

While the choice of what fund to invest in is a major decision that has tangible consequences for a stable and abundant financial future, the everyday choices that 
consumers and citizens are asked to make are also subject to choice fatigue and analysis. Along these lines, Iyengar and Lepper (2000) showed that choice could literally be "demotivating" even in these everyday cases. The researchers set up an experiment in a grocery store with a table of jams. On the table were either six jams or 24 jams, participants tasted as many jams as they wanted and were offered a $\$ 1$ coupon toward a purchase. When faced with 24 choices, consumers stopped at the table more than when only six jams were displayed, showing that people are more "attracted" to extensive choice, which is in line with Schwartz's (2009) observation that more extensive choice represents more freedom and therefore considered better for the person making the choice. However, after looking at the choices, more participants from the smaller choice group made a decision to buy a jam than the larger choice group. The implication here is that if there are too many choices people may not make a choice, however when we study television, even with many choices people still watch entertainment and gather information.

In a second experiment by Iyengar and Lepper (2000), college students were given a choice of doing an extra credit assignment. One group had six choices of topic to write on and the other group had 30 choices. The smaller choice group overwhelmingly turned in a completed assignment, which was also of a higher quality than the larger choice group. Thus, even with the reward of extra credit, and the same amount of work assigned, these students' results provide further context in which the more choice we have the less we are able to perform, even when it is to our benefit. 
Even in situations that are contingent on personal satisfaction, larger choice pools are still demotivating and lead to dissatisfaction. Iyengar and Lepper (2000) conducted a third study that explored both amount of choice and satisfaction of choice in choosing a flavor of Godiva chocolates. Participants were given six flavors or 30 flavors with one group in each condition asked to choose one. A third group was given the choice to not choose. As might be expected, the fewer choices encountered, even in something so enjoyable as chocolate, the higher the satisfaction. The groups that made no choice and were simply given a taste of chocolate were less satisfied.

The research presented here shows that, in a broad range of circumstances, more choice leads to a breakdown in the process of making a decision. The interesting thing to be gleaned here is that we seem to want choices, we want the freedom to choose what we want, but we cannot make satisfying decisions when too many choices are presented.

If we apply this idea of too many choices to a digital landscape that is oriented to numerous choices and fast decision-making, we must explore the concept of choice overload more fully. Choice overload may lead to the action of not choosing or being unsatisfied with a choice made. The number of choices may not be the deciding factor here, instead the threshold for choice overload may be the conceptual place research must turn to as the media landscape becomes accessible at any hour of the day, with nearly any content or outlet conceivable.

\section{Choice Overload and the Current Media Environment}

Schwartz (2009) argues that too much choice can be debilitating, leading to no choice or an unsatisfactory choice. There is, however, some contention as to whether or 
not people actually experience choice overload and how to define it. The concept of overload is explored throughout many disciplines including retail (Kahn and Lehmann, 2001) business research (Malhotra, 1984), and psychology (Iyengar, Jiang, \& Huberman, 2003). Choice is also implicated in the concept of information overload; having many choices is logically based on having several options, and in the Internet age, this means having abundant choice. Bawden, Holtham, and Courtney (1999) point to the irony of technological innovation and Internet access, which provides part of the equation for choice overload, "the greater amount of information available," (p. 250).

In a meta-analysis of 50 choice-overload experiments, Scheibehenne, Greifeneder, and Todd (2010) found that "no sufficient conditions could be identified that would lead to a reliable occurrence of choice overload," (p. 418). This leaves research in the rut of continuously trying to find the correct number of choices to present to participants, but the real-world fact is that people are forced to make more and more decisions every day, and with increasingly easy Internet access "the modern information environment...presents us with information in forms with which our senses, and prior experiences, are ill-equipped to deal," (Bawden et al., 1999, p. 251). The term information overload is "used to convey the notion of receiving too much information," and has been conceptualized in marketing research as "comparing the volume of information supply... with the information capacity of an individual," (Eppler \& Mengis, 2004, p. 326). The factors in this case are the distance between the time to make a choice and the amount of choice available. Similar to other choice research the logic is, 
"information processing requirements > information capabilities", which leads to overload (Eppler \& Mengis, 2004, p. 326).

If having more choices means that we have information overload looming over us at all times, how is it possible to make it through a day? Much research examines information overload in the context of consumer overload, and the mechanisms that are employed by consumers to combat the feelings of being overwhelmed and debilitated by choices. "When presented with "too much" information, consumers may become confused, so that they are unable to effectively and efficiently process the information, and/or they may adopt some heuristic processing," (Malhortra, 1984, p. 438). Common heuristics employed can include what Iyengar and Lepper (2000) point to in their research: choosing what is familiar or choosing not to choose. Understanding not only what choice consumers make, but how satisfied they are after making the choice is an important measure.

\section{Satisfaction}

Satisfaction varies among individuals. One person may feel satisfied about a given issue or choice, while someone with the same circumstances may not feel satisfied. Satisfaction, in general terms, is an individual feeling; as such it is difficult to define it for groups of people.

Satisfaction, as a measure is used in many ways from consumer satisfaction in purchases to psychological needs being met. Using satisfaction as a way to understand how people are feeling about a choice makes sense as an outcome as it covers a general understanding and points to a motivation. In making a digital television choice, one 
motive for choosing a particular show is satisfaction with that content. It is, in essence a tangible effect of a particular choice.

People have numerous reasons for why they feel a certain way, however the different approaches to defining satisfaction seek to generalize and predict what would influence feelings of satisfaction or dissatisfaction. Zhang and Fitzsimons (1999) look at satisfaction as part of the decision process "satisfaction...is associated only with the decision outcome choice," (p. 193), meaning that rather than looking at what an audience member brings to the decision from outside the process of choosing, their research measures satisfaction as a result of the process. This is in the context of product and marketing research but bears a similarity to other approaches to satisfaction in that the consumer or audience member is asked to look at attributes of different products or media and examines the satisfaction throughout the process. For example, if one is looking at a collection of similar products the pertinent question may be: are the characteristics of each product different enough to make the decision simpler, or are they so similar that people will have a difficult time choosing between them? On the other hand, "option limitation (i.e., making one option unavailable from a set of equally attractive options) decreases choice-process satisfaction," (Zhang \& Fitzsimons, 1999, p. 194). This is in line with Schwartz's (2009) assertions that people want the freedom to choose, even if the evidence shows that more choice is not more satisfying.

The anticipation of satisfaction perspective (Shiv \& Huber, 2000) takes a cognitive approach to looking at consumer choice. This research focuses on what the consumer might expect and how that will affect their choices. Shiv and Huber (2000) 
"propose that when anticipating satisfaction, the consumer forms mental images related to one or more of options, and the final decision is likely to be based on the focus of these imagery-related processes," (p. 202). In similar research in the vein of consumer research, Houston, Sherman, and Baker (1991), look at choice from the perspective of feature matching and the role of satisfaction in both pre-choice and post-choice processes. They found that when products are not similar enough to compare, or in other words there are too many choices between products, people tend to be less satisfied, however, when comparing similar features between products, satisfaction is higher. This can be compared to Internet and television choice - there are many products to consume, which makes the decision process difficult and thus, less satisfying.

These approaches to defining satisfaction through choice share the notion that a need is being met, and whether that need is met or not has implications for feelings of satisfaction. In communication research, the uses and gratifications tradition conceptualize media behavior in a similar way (Katz \& Blumler, 1973). However, in order to operationalize satisfaction, one must turn to the psychological basis of these feelings. One way of doing this is to look at the inherent components of individual's satisfaction.

Self-determination theory, or SDT, (Deci \& Ryan, 1975) seeks to understand the inherent factors of well-being or satisfaction. Satisfaction, according to selfdetermination scholars, requires meeting "three innate psychological needscompetence, autonomy, and relatedness — which when satisfied yield enhanced selfmotivation and mental health and when thwarted lead to diminished motivation and well- 
being," (Ryan \& Deci, 2000, p. 68). Beside these three needs, there must also be a motivation for doing a task. While there are intrinsic and extrinsic motivations, and scholars have explored the differences, the main point is that motivation must come from somewhere, either from within oneself or from an external source. In the case of entertainment, human nature has sought out story-based activities for centuries. Since the time of Homer singing epics in the Greek court, people are "a storytelling species" (Clark, 2011, p. 1). The main motivation for storytelling in general is to provide a way to explore real life situations and understand what they mean for the individual, "this virtual reality, this substitute experience, prepares us for resolving the conflicts of the real world" (Clark, 2011, p. 2). Based on this notion, it is obvious that people are indeed motivated to consume television.

Looking at the motivations for doing a given task connects back to Schwartz (2009) and his supposition that more choice leads to demotivated behavior in a largechoice environment, and that motivation must be present. However, meeting the basic needs in an activity is a sound place to look at satisfaction.

\section{Autonomy}

Autonomy, according to Ryan and Deci (2000), means, "volition- the organismic desire to self-organize experience and behavior and to have activity be concordant with one's integrated sense of self," (p. 231). This definition is taken from a number of sources (Angyal, 1965; deCharms, 1968; Deci, 1980; Ryan \& Connell, 1989; Sheldon \& Elliot, 1999), which have all helped in the development of the SDT to culminate in this concept. In simple terms it means the freedom to do what is necessary for both one's well-being 
and to follow one's motivations, be they intrinsic or extrinsic. The SDT proceeds on the basis that people in general want to move forward in their lives and be satisfied with their life (Deci \& Ryan 2000; Ryan \&Deci, 2000). Ryan, Rigby, and Przybyliski (2006) applied SDT to online gaming and the motivations of individuals to participate in a virtual world. Citing Deci and Ryan's 1980 and 2000 definition of autonomy as volition they expand that "when activities are done for interest or personal value, perceived autonomy is high," (p. 349). This is relevant for television choice as the landscape lends itself to autonomy. We have many choices, and many outlets that allow a consumer to be free from the confines of scheduling on the part of the producer.

\section{Competence}

The second component of SDT is competence, which is defined as "a need for challenge and feelings of effectance,” (Ryan, Rigby, \& Przybylski, 2006, p. 349; White, 1959; Deci, 1975). In the context of education, Niemiec and Ryan (2009) apply SDT to students and teachers. This takes a practical application of the components and recommends that "students' competence can be supported by educators' introducing learning activities that are optimally challenging, thereby allowing students to test and to expand their academic capabilities," (p. 139). This is a logical step for application, as people are more satisfied with their tasks, they will perform better, be it in gaming situations or educational settings. Competence, in regard to television, can be understood as the skills needed to navigate the many choices in the media landscape. It is a factor in understanding how people use media and how much they enjoy it, for instance if an 
individual is unfamiliar or uncomfortable with online environments, they will not be satisfied with making choices in the digital environment.

\section{Relatedness}

Relatedness is the final component of needs satisfaction and is defined as "the desire to feel connected to others," (Deci \& Ryan, 2000, p. 231). This is explored in Niemiec and Ryan (2009) for practical application, "people tend to internalize and accept as their own the values and practices of those to whom they feel, or want to feel, connected, and from contexts in which they experience a sense of belonging," (p. 139). In other words, relatedness is an inherent social situation that individuals seek.

Taking each component together, it is clear that satisfaction in a given context is complex, but the set of autonomy, competence, and relatedness is a place to start. In regard to the motivations for a given task, this may be more specific depending on the area of research.

The end result in a decision process (whether in purchasing behavior or media selection) is how one feels about the choice made, or an individual's satisfaction in the choice. This process is made increasingly individualized by the nature of this "modern information environment" which allows the audience members to not only choose what and how, but when to use an outlet, "viewing patterns that had been enshrined as laws, such as flow, now appear washed away with the click-accessibility of Internet TV," (Simon \& Rose, 2010, p. 52). This technological development adds another layer of complexity to the choice process: customization. 


\section{Customization}

Customization, as a concept, encompasses the audience member's ability to decide what to consume, however it also relates to the producer's role in providing certain options to the consumer. In marketing research there are several approaches to dealing with customization (Valenzuela, Dhar, \& Zettelmeyer, 2009). Self-customization is generally defined as "the process by which consumers seek to customize offerings to their own preferences," (Valenzuela et al., 2009, p. 754). Another phenomenon that is related is mass customization. Mass customization refers to "the ability to provide customized products or services through flexible processes in high volumes and at reasonably low costs," (Silveira, Borenstein, and Fogliatto, 2001, p. 1). These terms are related but should not be used interchangeably.

The differences between mass and self-customization have to do with producers of content and the audience members' ability to produce and choose. The mistake in combining the concepts is understandable, as the Internet age has allowed for individualized mass customization, or what could be called mass self-customization. From a production view, mass self-customization means that the audience or consumer has the ability to decide what they want in a product, however, "mass customization presents a paradox by combining customization and mass production, offering unique products in a mass produced, low cost, high volume environment," (Duray, 2002, p. 314). This is not a new idea, but with the changing landscape of Internet and mobile devices, and phenomena such as customized advertisement tactics (Norberg \& Dholakia, 2003), 
consumers are able to shift or control their own input, but companies are also able to target an audience based on massive amounts of personal information. In essence, these advancements in information gathering lead the producers into a role of a personalized choice process that is offered to a person, based on what is known about that individual.

From the production side "companies are approaching mass customization with caution because it requires that they correctly uncover individual preferences and provide products that fit those preferences," (Valenzuela et al., 2009, p. 754), this means that it is difficult to understand what consumers want especially in an age with more and more access on the part of the consumer. In the digital landscape, one way that customization can be wrongly executed is in the quality of the data provided (either knowingly or unknowingly) by the audience members (Norberg \& Dholakia, 2004), this in turn leads to dissatisfaction for the consumer because the content or messages they want will not appear for them in an interface that is easily obtainable.

In order to present the desired content to a viewer, two methods of customization have been explored: by-alternative customization and by-attribute customization. Byalternative customization refers to a decision process that "forces the consumer to customize by constructing their most preferred option from a set of fully specified products," (Valenzuela et al., 2009, p. 755). The by-attribute customization requires consumers to "construct the desired level for each of the product's attributes individually," (Valenzuela et al., 2009, p. 755). These are based on decision processes by 
consumers and may be applicable to digital media and the format of content available. ${ }^{1}$

The downside to individual choices in by-attribute customization is that people must make more and more decisions, rather than just choosing one product over another product, but "by-alternative customization reduces choice difficulty, enhances satisfaction, and increases the probability that the customized option will actually be purchased," (p. 762).

Valenzuela et al. (2009) attribute the lower levels of difficulty in choosing through by-alternative customization "not only is due to the reduced choice complexity and information overload but also is driven by the notion that trade-offs among competing characteristics are less explicit," (p. 762). This is a relevant finding for the study of television, as stated above, television watching is a normal experience in this culture, therefore people are normalized to how it works. If the tailoring or customization that is happening behind the scenes of the medium used is normal or "less explicit" then people may not be aware of how their choices are constrained by production. This is a limited notion, as people do decide what to watch, but there are a limited number of choices, these choices are limited even more by customization, by either the audience or the producer. The other side of this process is that the consumer is aware of the customization happening on their behalf, this may have an impact on the satisfaction from a choice.

\footnotetext{
${ }^{1}$ Valenzuela et al. (2009) found that people using the attribute process of customization tend to be in a middle ground in both price and number of options and choose each attribute of a product based on a "trade-off" mentality.
} 
Uricchio (2005) claims, “each new means of extending the viewer's control seem $[\mathrm{s}]$ to entail either unwanted side-effects, or to whet the appetite for new types of control," (p. 240), this points to the spiral of consumption that drives new technology. When a new form comes out, consumers tend to rush to embrace it. This is true for both consumers and producers in the area of customization, but an interesting gap in the study of customization effects for consumers may be in the amount of knowledge and input people actually have toward their personal customized messages and content in television. This said, people still go through a decision process - albeit from a selected amount of options on the part of the producer or by means of heuristics employed on the part of the consumer. This means that there is a relationship between the audience member's active role through providing information to producers about their preferences and in the outlet they turn to for their 'customized' viewing habits of media.

Audience-members fall somewhere between being active and being passive. As research has shown, people engage in heuristics when making a decision. Heuristics can also be defined as "problem solving strategies" (Lau \& Redlawsk, 2001, p. 952). The need for these shortcuts is necessary, as information overload becomes a more prominent issue in the digital age. They allow us to understand how to interpret and communicate, "as the sheer quantity of information becomes large, human judgment tends to become more reliant on simplifying rules or heuristics that either take advantage of only partial information or process information in incomplete ways," (Slovic, MacGregor, \& Peters, 1998, p. 17). These cognitive processes are done in the background of a decision. As the 
recent television landscape differs from traditional television viewing, the engagement level of the audience is an important point. Perhaps it is not that the audience is entirely passive or completely active, but that working in tandem with the media, people who get satisfaction from television most likely have tools that help them navigate the medium. Further to the point, the background decision-making in the form of shortcuts implies that the audience is indeed engaged in some form.

Therefore, this study presents two hypotheses based on choice, customization, satisfaction:

H1: Individual satisfaction is lower when given a larger television choice pool than individuals given a smaller choice pool.

H2: Participants who are aware of individual customization in a given viewing choice pool will report higher satisfaction than participants who are unaware of individual customization. 


\section{Data and Methods}

This study explores the process of choice in the digital television landscape and the satisfaction that follows a viewing choice. As self-reports can be unreliable, I conducted a $2 \times 2$ survey-experiment designed to test the effect of manipulation the amount of choice and the level of customization about participants self-reported viewing satisfaction.

\section{Participants}

Participants were recruited via Amazon's Mechanical Turk. To be eligible, participants were required to be 18 or older and watch television in some capacity. After clicking the experiment's solicitation on Mechanical Turk, participants saw an informed consent form. If participants assented, they could continue to the experiment ${ }^{2}$. The study successfully recruited 606 viable participants from 1458 initial responses on Mechanical Turk (see Table 1 for a descriptive overview of the sample).

\footnotetext{
${ }^{2}$ IRB approval number: 206831-18
} 
SO MANY CHOICES

Table 1 - Sample Demographics

\begin{tabular}{lcc}
\hline Characteristic & Number & Percent \\
\hline \hline Gender & & \\
\hline Women & 301 & 50 \\
Men & 305 & 50
\end{tabular}

Education

Less than high school $\quad 12$

$\begin{array}{lll}\text { High school or GED } & 99 & 16\end{array}$

$\begin{array}{lll}\text { Some college (no degree) } & 187 & 31\end{array}$

$\begin{array}{lll}\text { Associate or technical degree } & 71 & 12\end{array}$

$\begin{array}{lll}\text { Bachelor's degree } & 179 & 29\end{array}$

$\begin{array}{lll}\text { Master's, Professional, Doctoral degree } & 58 & 9.5\end{array}$

\begin{tabular}{lcc} 
Age & & \\
\hline $18-25$ & 138 & 23 \\
$26-35$ & 210 & 34.6 \\
$36-45$ & 96 & 15.8 \\
$46-55$ & 83 & 13.8 \\
$56-65$ & 69 & 11.5 \\
66 and older & 10 & 1.7
\end{tabular}

\section{Marital Status}

\begin{tabular}{lcc}
\hline Single, never married & 307 & 51 \\
Married & 214 & 35 \\
Divorced & 57 & 9 \\
Widowed & 13 & 2 \\
Separated & 9 & 1 \\
Decline to answer & 6 & 1 \\
Income & & 45 \\
\hline Less than \$24,999 & & 31 \\
\$25,000 to \$49,999 & 272 & 20 \\
\$50,000 to \$99,999 & 190 & 3 \\
De0,000 or more & 123 & .17 \\
Decline to answer & 20 & 1 \\
Race & 1 & 5 \\
\hline American Indian or Alaska Native & & 5 \\
Asian or Pacific Islander & 3 & 5 \\
Black/African American & 32 & 3 \\
Wispanic/Latino & 47 & 5 \\
Other & 29 & \\
\end{tabular}


To create the final sample, I excluded participants who failed to complete all questions and those who did not take enough time to complete the survey: 10 minutes to view a full clip (each clip was around 3 minutes $^{3}$ ) and to complete the questionnaire. The participants were paid between .15 and .25 cents for completing the experiment. No personal information linking the participants to their answers was collected, ensuring confidentiality.

\section{Procedures}

Participants recruited from Mechanical Turk were directed to Qualtrics as the experiment was entirely available online. After informed consent, participants filled out a four-item questionnaire evaluating what types of television they favor: comedy, drama, animated, or crime and asked to list their three favorite shows. Then participants were randomly assigned to one of four conditions: high choice with customization $(n=159)$, high choice with no customization $(n=149)$, low choice with customization $(n=148)$, or low choice without customization $(n=150)$. They were given a listing of popular television show clips and asked to choose one.

Participants in the customization groups were informed that the list of shows was customized for them, which was a label only, meaning all participants were shown random clips. The other participants were not told that their choices were informed by customization and directly shown the list of television clips. High choice was constituted by offering participants 25 choices; low choice was represented by 5 choices. After they

\footnotetext{
${ }^{3}$ Each clip varied from the shortest, "The Simpsons" clip at 52 seconds to the longest, "So You Think You Can Dance" clip at 3 minutes 14 seconds.
} 
chose and watched a clip, participants answered a general question of how satisfied they were specifically with the clip and then filled out a modified version of the basic psychological needs scale (Deci \& Ryan, 2000) to measure their subsequent general satisfaction. Then participants were asked general demographic questions (see Table 1) and the general time spent on the study as a whole was 10 minutes. (see Appendix A for survey).

\section{Materials}

To explore the relationship between choice, television, and satisfaction with an experiment, I selected a pool of clips from popular TV shows to use as stimuli. The range of possible programming was based on Nielsen ratings that identified the top television shows in the United States for adults ages 18 to 49. As access to some of these shows was difficult and given that many of them are made for children under 18 years old, some shows were not included in the choice pool. ${ }^{4}$ To ensure the clips were choices that individuals would choose to watch, a selection of the remaining top shows were pretested to assure comparability. By normalizing the enjoyability of individual clips, my goal was to remove a possible source of variance in satisfaction, allowing the influence of the amount of choice and the perception of customization to be seen more clearly.

To select a pool of enjoyable clips, I pretested 30 clips on Mechanical Turk by asking people to rate their satisfaction on a scale of 1 to 5 via survey. Those responses where gathered, and the average satisfaction scores determined which clips to include in the final survey. Each possible clip was pretested with at least 20 participants who were

\footnotetext{
${ }^{4}$ See full list of programs in Appendix B
} 
18 years of age and older and resided in the United States. Clips that were not viewed by at least 20 participants in the pretest were rejected outright. Participants were asked to view the clips and self-report how much the clip was enjoyed. The final list of shows the participants chose clips from was: Big Bang Theory, 2 Broke Girls, Castle, Criminal Minds, Grey’s Anatomy, How I Met Your Mother, Mike and Molly, Modern Family, NCIS, New Girl, Scandal, Simpsons, and So You Think You Can Dance. In order to present 25 choices to the high choice groups of participants, more than one clip of these pretested shows was added to the survey.

\section{Experimental Manipulations}

Again, this study employed a 2x2 experimental design in which the amount of choice and the stated presence (or absence) of individual customization were manipulated.

\section{Choice}

Choice was manipulated by offering two randomly assigned conditions. The lowchoice condition offered five options for participants. Participants in the high-choice condition were shown 25 choices. The number of choices for each condition follows previous research; the definition of a large choice pool can range from 24 to 59 and a small choice pool ranges from two to six choices depending on the context (Iyengar, Jiang, \& Huberman, 2003; Iyengar \& Lepper 2000). Qualtrics was set to display a random selection of the appropriate number clips for either condition following random assignment to the low or high treatment. Participants were able to view only one clip and were not able to change their choice. 


\section{Customization}

Manipulation of customization and the possible effects it has on choice in television in the online environment was accomplished by labeling the choices offered to participants. To be clear: customization did not actually occur. In the first condition, participants saw a screen that said, "The following clips have been personally customized for your viewing choice based on your viewing preferences and given information" before they were shown the options. While the screening questions were intended to give participants in the customized groups the feeling of real customization, the clips they received in their choice group were completely random and no choice pool was formed based on genre preference. Meanwhile, the second group received no notification that their choice pool had been customized for them (and, in fact, there was no customization in this condition either). Instead, they received a screen that said, "Please choose a clip from the following list of shows and view it."

\section{Measures}

Satisfaction is the primary dependent variable and was measured in two ways after participants had viewed a clip of a television show. I used a modified version of the basic psychological needs scale (Deci \& Ryan, 2000) with a Cronbach alpha of .85 to assess satisfaction. The scale consists of 21 items and uses a 7-point Likert scale response pattern. As a complement, an additional question on the questionnaire asked the nominal question of "Were you satisfied with your viewing choice?" with a 7-point Likert scale response pattern (See Appendix A for full questionnaire). 


\section{Results}

To address both H1: An individual's satisfaction level is lower when faced with a larger television choice pool, and H2: Participants who are aware of individual customization in a given viewing choice pool will report higher satisfaction than participants who are unaware of individual customization I report both operationalizations of satisfaction across the 4 experimental groups in table 2 .

Table 2: Viewer Satisfaction

\begin{tabular}{|c|c|c|c|c|c|c|c|c|}
\hline \multirow{2}{*}{$\begin{array}{l}\text { Group } \\
\text { Overall }\end{array}$} & \multicolumn{4}{|c|}{ Satisfaction (one question) } & \multicolumn{4}{|c|}{ Basic Need Satisfaction Scale } \\
\hline & $N$ & Mean & $S D$ & $\begin{array}{l}\text { ANOVA } \\
P \text { value }\end{array}$ & $N$ & Mean & $S D$ & $\begin{array}{r}\text { ANOVA P } \\
\text { Value }\end{array}$ \\
\hline & 606 & 5.54 & 1.71 & .038 & 606 & 4.99 & .97 & .125 \\
\hline \multirow{2}{*}{$\begin{array}{l}\text { High Choice } \\
\text { with } \\
\text { Customization }\end{array}$} & $N$ & Mean & $S D$ & $\begin{array}{r}\text { Tukey } \\
\text { P value* }\end{array}$ & $N$ & Mean & $S D$ & $\begin{array}{l}\text { Tukey } \\
\text { P value }\end{array}$ \\
\hline & 159 & 5.79 & 1.70 & .021 & 159 & 4.04 & .96 & .742 \\
\hline \multirow{2}{*}{$\begin{array}{l}\text { Low Choice } \\
\text { with } \\
\text { Customization }\end{array}$} & $N$ & Mean & $S D$ & $\begin{array}{l}\text { Tukey } \\
\text { P value }\end{array}$ & $N$ & Mean & $S D$ & $\begin{array}{r}\text { Tukey } \\
\text { P value }\end{array}$ \\
\hline & 148 & 5.56 & 1.58 & .654 & 148 & 4.87 & 1.04 & .427 \\
\hline \multirow[t]{2}{*}{$\begin{array}{l}\text { High Choice no } \\
\text { Customization }\end{array}$} & $N$ & Mean & $S D$ & $\begin{array}{r}\text { Tukey } \\
\text { P value }\end{array}$ & $N$ & Mean & $S D$ & $\begin{array}{l}\text { Tukey } \\
\text { Pvalue }\end{array}$ \\
\hline & 149 & 5.58 & 1.72 & .705 & 149 & 5.11 & .88 & .900 \\
\hline \multirow[t]{2}{*}{$\begin{array}{l}\text { Low Choice no } \\
\text { Customization }\end{array}$} & $N$ & Mean & $S D$ & $\begin{array}{r}\text { Tukey } \\
\text { P value }\end{array}$ & $N$ & Mean & $S D$ & $\begin{array}{l}\text { Tukey } \\
\text { P value }\end{array}$ \\
\hline & 150 & 5.32 & 1.81 & .021 & 150 & 4.92 & .99 & .742 \\
\hline
\end{tabular}

*Tukey p values are taken from comparisons from the high choice with customization post-hoc test.

Looking at the single question of satisfaction, a one-way ANOVA revealed significant differences between groups $(F=2.821, d f=3 / 602, p=.038)$. A post-hoc Tukey analysis revealed the significant difference between 2 of the 4 groups of participants $(p=.021)$, the high choice with customization group $(N=159, M=5.79)$ and the low choice 
with no customization group $(N=150, M=5.32)$. This difference is the opposite of what is predicted by $\mathrm{H} 1$ in that the high choice group reported higher satisfaction. For $\mathrm{H} 2$, the data supports the researchers' prediction that awareness of customization will result in higher satisfaction levels.

Looking at the Basic Needs Scale to measure satisfaction a one-way ANOVA showed no significant differences between the 4 groups $(F=1.921, d f=3 / 602, p=.125)$. A comparison looking more broadly at groups of high choice $(N=308)$ and low choice $(N=298)$, setting aside customization as a factor, using a T-test provides another approach to testing the choice hypothesis. For both the single question of satisfaction and the Basic Needs Scale, no significance was found between these larger groups.

The researchers also ran an Independent T-test for the single question of satisfaction looking at groups of customized $(N=307, M=5.68, S D=1.64)$ and not customized ( $N=299, M=5.40, S D=1.77)$ excluding high choice or low choice as a factor and found a significant difference between groups $(t(604)=-1.99, p=.035)$. The Independent T-test for the Basic Needs Scale measure of satisfaction did not show a significant difference $(t(604)=.80, p=.267)$. 


\section{Discussion}

This study explores the consequences of an increasingly familiar experience: the difficulty in making choices in the online television market. Scrolling though Netflix or any other streaming service to find something to watch has become a normal occurrence for consumers. This study seeks to understand a small part of what is happening to our satisfaction when we are faced with many choices in digital media and what part customization plays in that satisfaction.

This study shows that participants in the high choice with customization group are the most satisfied with their viewing choice and participants in the low choice with no customization group are the least satisfied. This is interesting because it goes against my prediction that a high choice environment leads to less satisfaction but supports the prediction that a perception of customization leads to more satisfaction. In regard to choice, this finding goes against a large body of research showing that when people are confronted with more choices they are less likely to be satisfied and have difficulty making a choice at all (Iyengar \& Lepper, 2000; Schwartz, 2009). In the case of online television, these findings point to a desire to have all the choices possible as well as customized specifically for the individual viewer. In regard to customization, it makes sense that this raises satisfaction, the nature of our society puts a premium on wanting things made just for us, conjuring words such as "tailored" or "bespoke". This makes us feel more satisfied because it signals that the selection of media was presented with us in mind. This is even more interesting in the case of this study because the customization 
stimulus was a placebo and it still heightened participants' satisfaction just to be told that their selection was customized for them.

What may also be a factor in this study is that people who are immersed in the online television culture will most likely be able to navigate that world more easily, thus being normalized to a high choice environment. This study was presented entirely online, meaning that all participants have an understanding of navigating the digital world. Therefore, the larger choice pool is advantageous for them. This tells us that people want more choices when it comes to their media, however it also points to the ability to adapt to a larger pool of choices in general. With more online access comes more content, and in order to process that content viewers must make choices. Iyengar and Lepper (2000) posit that "it is not that people are made unhappy by the decisions they make in the face of abundant options but that they are instead unsure - that they are burdened by the responsibility of distinguishing good from bad decisions." (p. 1004). This is an interesting notion and I would argue that television choice does not seem to be "a burden". In the area of television and storytelling as a society, the higher amount of choices is advantageous. However, we see anecdotally that we scroll through massive amounts of content to make decisions, and have difficulty making a choice. However, in this area, the threshold for the "paralysis" of choice may be higher.

In the real online media environment, companies are capable of collecting viewing habits, asking questions about content preferences, and allowing people to create a viewing history that informs how the platforms present choices to the consumers. People tend to be happy when they see the content that they want, this is intuitively true. 
It also lines up with theories on "by alterative and by-attribute customization": Byalternative customization refers to a decision process that "forces the consumer to customize by constructing their most preferred option from a set of fully specified products," (Valenzuela et al., 2009, p. 755). The by-attribute customization requires consumers to "construct the desired level for each of the product's attributes individually," (Valenzuela et al, 2009, p. 755).

While people may be overwhelmed with many new choices, if they know what they prefer ahead of time, and are offered that choice through a customization mechanism they will be more satisfied. In this study, I asked participants to list out their favorite shows before they saw the clips, thus they had something in mind when they looked at the selections. This helped them think about what was closest to their favorite in the list of shows they saw. This is in line with choice theory literature in that when people are confronted with a choice, they may choose what is familiar instead of what is unknown (Schwartz, 2009). This means that content is important, which we know, and as we see in the current online media environment, no single outlet has every piece of content that a viewer might want. This treads into another area of study not covered by the present study which warrants more in-depth analysis as media changes according to demand. Considering the number of content choices on a single outlet, and in addition the choices about outlets adds another layer that viewers must navigate. Audience members must decide how many streaming services to which they will subscribe; a lack of access to favored titles offers another possible limitation to satisfaction. Consumers must also consider if they even have access through Internet and the cost of multiple subscriptions. 
While this is a side note to the hypotheses in this study, it is noteworthy and bears upon the reasons that people might be satisfied in the higher choice environment.

The area of online television is still an emerging and changing market. Content for different channels is coming from both the viewing platforms themselves (such as Netflix and Hulu), as well as traditional television producers. For example, Orange is the New Black was produced by Netflix, and the creator, Jenji Kohan, has commented on the 'brave new world' of television: "I love being on the new frontier. I love being first out of the gate. It's really, really fun, because I think it is the future in a lot of ways, of how people consume media, and it's great to be in there early.” (Kohan, 2013). This future Kohan is talking about fuels the fire for on-demand television. One could argue that this demand coupled with well-known and respected television content creators, like Kohan (who also created Weeds on Show Time) is what is pushing networks such as HBO and Disney to adopt the on-demand model. ${ }^{5}$

While Kohan claimed to be excited by being at the forefront of the digital and ondemand world of television, she commented on the fact that the days of co-watching are gone. Perhaps it is not positive from the producer's point of view for the public to access media whenever and wherever desired. Should the viewer be trusted to have constant access as we become more used to binge-watching content? Even Kohan is conflicted about the model of constant access, but commented that "on the other hand, how often in life do you get just what you want when you want it? There's something very satisfying

${ }^{5}$ In 2010, HBO launched HBO Go, an online service that allows subscribers to watch HBO content without necessarily subscribing through a cable company. Disney launched Disney+ in 2019, their streaming service hosting most Disney owned content. 
[about that]." (Kohan, 2013). This observation is at the heart of why Internet television and understanding the process of choice we go though in such a massive content market is important. Society is increasingly going to a market that is on demand, personalized, and filled with choices. Theoretically a consumer can have what they want when they want it, and that will increase satisfaction.

\section{Limitations}

While this study is an interesting view of online television and how people react to the massive amount of choice we have in media, it is only a small snapshot of a larger issue. Its findings should be viewed with several limitations in mind.

First, and perhaps most importantly, satisfaction is difficult to measure. Looking at the two measures of satisfaction in this study, the Basic Needs Scale showed no significant results for any groups while the single question of satisfaction did show significant results. This difference is understandable for this experiment and how it was designed. The single, direct question, "Are you satisfied with this television clip?” was asked after the participant viewed the clip. This is a strong enough question to get an accurate measure of how a participant felt in the moment. A scale that seeks to capture general satisfaction with a series of questions none of which directly asks about the clip itself does not capture satisfaction for that moment. While the scale is a strong measure of basic needs satisfaction, it is not directed at the clip as the specific source of satisfaction. The questions in the scale are directed to the participant and their overall satisfaction in life and television in general. As we know, television is an important facet of social life, however it is not as important as how capable one feels, or if one likes the people around 
them. Thus, while this scale is a tested and capable measure of satisfaction, for this particular study, it did not capture accurately the direct feelings from viewing the television clip.

Additionally, in this experiment, the stimulus for customization is a placebo. This approach was feasible with limited resources and thus practical for this study. A stimulus that does in fact compile and compute preference trends based on several inputs by a participant would capture better the concept of customization - and yet, even the placebo appeared to affect participants.

More broadly, an experimental design that is longitudinal would allow for data that shows a more complete picture, however time did not allow for that in this study. And, having more than 25 choices in the high choice group would more closely resemble the online television market. This study used 25 choices based on previous choice studies and their numbers of choices. However, those previous studies did not look at viewing choice specifically. Participants may react differently when faced with more than 25 choices for digital viewing given the abundance that they have been habituated to since the rise of cable in the 1980s.

The demographics of this study were fairly homogenous, and more diversity in the sample would make the findings more complete. On that note, the recruitment method could also be diversified. All the participants were individuals navigating an online medium through Mechanical Turk. While digital television does take some amount of user knowledge, many consumers are not so comfortable with online services as those found on Mechanical Turk. Meanwhile, “Turkers” may possess a higher level of 
technical sophistication than average Americans - which could, in turn, influence their comfort with Internet television and greater satisfaction with more choice.

Content is another limitation. This study only offered the most popular shows available at the time. The true nature of any online viewing platform is that there is a mixture of both content that one would want to view and just as much less enjoyable or popular content. Opinions on what is enjoyable vary from user to user, but this is a consideration and supports the idea of a larger choice pool that includes popular and less popular options in future research.

\section{Conclusion}

Streaming Internet television is more than a fad or trend; it is a shift in viewing habits that is here to stay. Understanding the factors that affect us as consumers is an important area of study. This study is one part of a larger conversation about how digital media is changing and what that means for society.

There is a larger societal conversation occurring about the use of personal data and preferences for marketing and information in general and having one's media customized allows companies to gather information from individuals. As we move more online, we allow more information out into the world. If you have the experience of Netflix showing more of the same show over and over again it is a double-edged sword. To choose similar content is to invite the streaming outlet to offer you more of the same, thus narrowing your experience of content and providing an echo chamber of things you've already watched. On the other hand, to give more and more information about ones' preferences is to share more with an online world. This is yet another choice the 
consumer must face in media choice, to share and have better customized results or not share and have similar content presented based only on viewing history.

Questions for future research in the area of digital television choice could be further inquiry into what, if any, amount of content would create what we see in previous research. Is digital television truly a place where more and more choice is better and more satisfying? I would hypothesize that there must be a limit, which would also help explain why customization is so important. When faced with so many choices, to understand how the choices are organized for individuals makes it easier to make a choice, and more satisfying when a choice is made. We must have some way of organizing the content, and consumers having some say in the process is important.

Consumers make more and more choices when it comes to watching television, the days of having three channels are gone, the audience has nearly unlimited options on what to choose. Producers are also rethinking how to provide content. The implications that this study brings to the body of work is that online television viewers are more satisfied with more content and they want that content presented specifically for them. In this period of history where we have "anytime, anywhere" access to media, Kohan's question of "how often can you get what you want?" is relevant, and the answer is now. 


\section{References}

Bawden D., Holtham C., \& Courtney, (1999). Perspectives on information overload. Aslib Proceedings, 51(8), 249-255. doi: 10.1108/EUM0000000006984

Bibel, S. (2013, May 21). TV ratings broadcast top 25: 'The Big Bang Theory' tops week 34 viewing among adults 18-49, 'NCIS' on top with the total viewers. $T V B y$ the Numbers. Retrieved from http://tvbythenumbers.zap2it.com

Bibel, S. (2013, June 14). Thursday cable ratings: 'Pawn Stars' wins night, 'Burn Notice', 'Swamp People', 'Gracland', 'Sullivan \& Son', \& more.TV By the Numbers. Retrieved from http://tvbythenumbers.zap2it.com

Carlson, M. (2006). Tapping into TiVo: digital video recorders and the transition from schedules to surveillance in television. New Media \& Society, 8(97), 97-115.doi: $10.1177 / 1461444806059877$

Chamberlain, D. (2010). Television interfaces. Journal of Popular Film and Television, 38(2), 84-88.doi: 10.1080/01956051.2010.483361

Dawson, M. (2010). Television between analog and digital. Journal of Popular Film and Television, 38(2), 95-100.doi: 10.1080/01956051.2010.483361

Deci, E. L. \& Ryan, R. M. (2000). The "what" and "why” of goal pursuits: human needs and the self-determination of behavior. Psychological Inquiry, 11(4), 227-268.

Duray, R. (2002). Mass customization origins: mass or custom manufacturing? International Journal of Operations \& Production Management, 22(3), 314-328.

Eppler, M. J. \&Mengis, J., (2004). The concept of information overload: a review of 
literature from organizational science, accounting, marketing, MIS, and related disciplines. Information Society, 20, 325-344.doi: 10.1080/01972240490507974

Gitlin, Todd (2000). Inside Prime Time. Berkley and Los Angeles, California: University of California Press.

Houston, D. A., Sherman, S. J., \& Baker, S. M. (1991). Feature matching, unique features, and the dynamics of the choice process: predecision conflict and postdecision satisfaction. Journal of Experimental Social Psychology, 27, 411430.

Iyengar, S. S. \& Lepper, M. R. (2000). When choice is demotivating: can one desire too much of a good thing? Journal of Personality and Social Psychology, 79(6), 9951006.doi: 10.1037//0022-3514.79.6.995

Iyengar, S. S., Jiang, Wei, \& Huberman, Gur (2003). How much choice is too much? Contributions to 401(k) retirement plans. Pension Research Council Working Paper: Wharton School, University of Pennsylvania.

Kahn, B. E. \& Lehmann, D. R., (1991). Modeling choice among assortments. Journal of Retailing, 67(3), 274-299.

Katz, E., \& Blumer, J. G. (1973-1974). Uses and Gratifications Research. The Public Opinion Quarterly, 37(4), 509-523.

Lau, R. R. \& Redlawsk, D. P. (2001). Advantages and disadvantages of cognitive heuristics in political decision making. American Journal of Political Science, 45(4), 951-971.

Malhotra, N. K., (1984). Reflections on the information overload paradigm in consumer 
decision making. Journal of Consumer Research, 10, 436-440.

Niemiec, C. P. \& Ryan, M. R. (2009). Autonomy, competence, and relatedness in the classroom: applying self-determination theory to educational practice. Theory and Research in Education, 7, 133-144.doi: 10.1177/1477878509104318

Norberg, P. A. \& Dholkia, R. R. (2003). Customization, information provision and choice: what are we willing to give up for personal service? Telematics and Informatics, 21, 143-155. doi: 10.1016/S0736-5853(03)00053-4

Przybylski, A. K., Ryan, R. M., \& Rigby, C. S. (2009). The motivating role of violence in video games. Personality and Social Psychology Bulletin, 35, 243-259.doi: $10.1177 / 0146167208327216$

Clark, R. P. (2011). From Homer to 9/11, how storytelling charts our survival [Web log post]. Retrieved from http://www.poynter.org/how-tos/newsgatheringstorytelling/writing-tools/145546/from-homer-to-911-how-storytelling-charts-oursurvival/

Ruggiero, T. E. (2000). Uses and gratifications theory in the $21^{\text {st }}$ century. Mass Communication \& Society, 3(1), 3-37.

Rummel, A. \& Feinberg, R. (1988). Cognitive evaluation theory: a meta-analytic review of the literature. Social Behavior and Personality, 16(2), 147-164.

Ryan, R. M. (1982). Control and information in the intrapersonal sphere: an extension of cognitive evaluation theory. Journal of Personality and Social Psychology, 43(3), 450-461.

Ryan, R. M. \&Deci, E. L. (2000). Self-determination theory and the facilitation of 
intrinsic motivation, social development, and well-being. American Psychologist, 55(1), 68-78.doi: 10.1037//0003-066x.55.1.68

Ryan, R. M., Mims, V. \& Koestner, R. (1983). Relation of reward contingency and interpersonal context to intrinsic motivation: a review and test using cognitive evaluation theory. Journal of Personality and Social Psychology, 45(4), 736-750.

Ryan, R. M., Rigby, C. S. \&Przybylski, A. (2006). The motivational pull of video games: a self-determination theory approach. MotivEmot, 30, 347-363. doi: $10.1007 / \mathrm{s} 11031-006-9051-8$

Scheibehenne, B., Greifeneder, R., \& Todd, P. M., (2010). Can there ever be too many options? A meta-analytic review of choice overload. Journal of Consumer Research, 37, 409-425.doi: 10.1086/651235

Schwartz, B. (2009). Incentives, choice, education and well-being. Oxford Review of Education, 35(3), 391-403.doi: 10.1080/03054980902934993

Shafir, E., Simonson, I., \& Tversky, A., (1993). Reason-based choice. Cognition, 49, 11 36.

Simon, R, \& Rose, B. (2010). Mixed-up confusion: coming to terms with the television experience in the twenty-first century. Journal of Popular Film and Television, 38(2), 52-53.doi: 10.1080/01956051.2010.483361

Silveria, G. D., Borenstein, D. \&Fogliatto, F. S. (2000). Mass customization: literature review and research directions. International Journal of Production Economics, 72, $1-13$.

Shiv, B. \& Huber, J. (2000). The impact of anticipation satisfaction on consumer choice. 
Journal of Consumer Research, 27, 202-216.

Slovic, P., MacGregor, D. G. \& Peters, E. (1998). Imagery, affect, and decision making. Unpublished manuscript, Decision Research, Eugene, Oregon.

Spear, H. J. \& Kulbok, P. (2004). Autonomy and adolescence: a concept analysis. Public Health Nursing, 21(2), 144-152.

Tamborini, R., Bowman, N. D., Eden, A., Grizzard, M., \& Organ, A. (2010). Defining enjoyment as the satisfaction of intrinsic needs. Journal of Communication, 60, 758-777.doi: 10.1111/j.1460-2466.2010.01513.x

Tversky, A. \& Kahneman, D. (1981). The framing decisions and the psychology of choice. Science, 211(4481), 453-458.

Uricchio, W. (2005). Television's next generation: technology/interface culture/flow. In Spigel, L. \& Olsson, D. (Eds.), Television After TV: Essays on a Medium in Transition (232-261). Duke University Press.

Valenzuela, A., Dhar, R., \& Zettelmeyer, F. (2009). Contingent response to selfcustomization procedures: implications for decision satisfaction and choice. Journal of Marketing Research 46, 754-763.

Van den Broeck, A., Vansteenkiste, M., De Witte, H., Soenens, B. \& Lens, W. (2010). Capturing autonomy, competence, and relatedness at work: construction and initial validation of the work-related basic need satisfaction scale. Journal of Occupational and Organizational Psychology, 83, 981-1002.doi:

$10.1348 / 096317909 x 481382$

White, R. W. (1959). Motivation reconsidered: the concept of competence. Psychological 
Review, 66 (5), 297-333.

Wilson, T. D., Lisle, D. J., Schooler, J. W., Hodges, S. D., Klaaren, K. J., \& LaFluer, S. J. (1993). Introspecting about reasons can reduce post-choice satisfaction.

Personality and Social Psychology Bulletin, 19, 331-339.doi:

$10.1177 / 0146167293193010$

Wilson, P. M., Rogers, W. T., Rodgers, W. M., \& Wild, T. C. (2006). The psychological need satisfaction in exercise scale. Exercise Psychology, 28, 231-251.

Zhang, S. \& Fitzsimons, G. J. (1999). Choice-Process satisfaction: the influence of attribute alienability and option limitation. Organizational Behavior and Human Decision Processes, 77(3), 192-214. 


\section{Appendix A}

Survey Questions:

1. Do you watch television on the Internet?

Yes, No

2. What source do you use most often for television online?

Blank response

3. Please rank the following television show genres from favorite to least favorite:

Drama, Comedy, Animated, Reality

4. What are your 3 current favorite television shows?

Blank response

[Customization manipulation]

[Choice manipulation]

Please choose a television show clip and view it.

5. Were you satisfied with the clip you watched?

$\begin{array}{lllllll}1 & 2 & 3 & 4 & 5 & 6 & 7\end{array}$

I was not at all satisfied I was somewhat satisfied I was very satisfied

Basic Need Satisfaction in General

Please read each of the following items carefully, thinking about how it relates to your viewing choice, and then indicate how true it is for you. Use the following scale to respond:

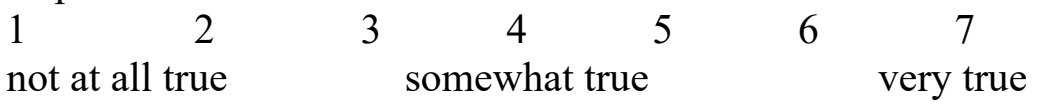




\begin{tabular}{|c|c|}
\hline Original Scale Questions (not used) $^{6}$ & Modification Scale questions (used) \\
\hline \multicolumn{2}{|l|}{ Autonomy } \\
\hline $\begin{array}{l}\text { 6. I feel like I am free to decide for myself how } \\
\text { to live my life. }\end{array}$ & $\begin{array}{l}\text { I feel free to decide for myself what television } \\
\text { shows to watch. }\end{array}$ \\
\hline 7. I feel pressured in my life. & $\begin{array}{l}\text { I feel pressured to decide what television shows } \\
\text { to watch. }\end{array}$ \\
\hline $\begin{array}{l}\text { 8. I generally feel free to express my ideas and } \\
\text { opinions. }\end{array}$ & $\begin{array}{l}\text { In general, I feel that I decide what television } \\
\text { shows to watch. }\end{array}$ \\
\hline $\begin{array}{l}\text { 9. In my daily life, I frequently have to do what } \\
\text { I'm told. }\end{array}$ & $\begin{array}{l}\text { In my daily life, I frequently have to watch } \\
\text { television that I do not choose. }\end{array}$ \\
\hline $\begin{array}{l}\text { 10. People I interact with on a daily basis tend to } \\
\text { take my feelings into consideration. }\end{array}$ & Same \\
\hline $\begin{array}{l}\text { 11. I feel I can pretty much be myself in my } \\
\text { daily situations. }\end{array}$ & $\begin{array}{l}\text { I feel the television shows I choose reflect who I } \\
\text { am in daily situations. }\end{array}$ \\
\hline $\begin{array}{l}\text { 12. There is not much opportunity for me to } \\
\text { decide for myself } \\
\text { how to do things in my daily life. }\end{array}$ & $\begin{array}{l}\text { There is not much opportunity for me to decide } \\
\text { what television shows to watch for myself. }\end{array}$ \\
\hline \multicolumn{2}{|l|}{ Relatedness } \\
\hline 13. I really like the people I interact with. & I really like the television shows I watch. \\
\hline $\begin{array}{l}\text { 14. I get along with the people I come into } \\
\text { contact with. }\end{array}$ & $\begin{array}{l}\text { I like the characters in the television shows I } \\
\text { watch. }\end{array}$ \\
\hline $\begin{array}{l}\text { 15. I pretty much keep to myself and don't have } \\
\text { a lot of social contacts. }\end{array}$ & I don't really watch television online. \\
\hline $\begin{array}{l}\text { 16. I consider the people I regularly interact with } \\
\text { to be my friends. }\end{array}$ & $\begin{array}{l}\text { I consider the television shows I regularly watch } \\
\text { to be a part of my life. }\end{array}$ \\
\hline 17. People in my life care about me. & Same \\
\hline 18. There are not many people that I am close to. & $\begin{array}{l}\text { There are not many television shows that I } \\
\text { enjoy. }\end{array}$ \\
\hline $\begin{array}{l}\text { 19. The people I interact with regularly do not } \\
\text { seem to like me very much. }\end{array}$ & $\begin{array}{l}\text { The characters in the television shows that I } \\
\text { watch regularly are people that might not like } \\
\text { me in real life. }\end{array}$ \\
\hline $\begin{array}{l}\text { 20. People are generally pretty friendly towards } \\
\text { me. }\end{array}$ & Same \\
\hline \multicolumn{2}{|l|}{ Competence } \\
\hline 21. Often, I do not feel very competent. & $\begin{array}{l}\text { Often, I do not feel very competent when } \\
\text { choosing a television show to watch. }\end{array}$ \\
\hline
\end{tabular}

${ }^{6}$ The original scale questions are listed here only to show what they were. The modified scale questions were the only ones presented to participants. 


\begin{tabular}{|l|l|}
\hline $\begin{array}{l}\text { 22. People I know tell me I am good at what I } \\
\text { do. }\end{array}$ & $\begin{array}{l}\text { People I know tell me I am good at finding } \\
\text { television shows online. }\end{array}$ \\
\hline $\begin{array}{l}\text { 23. I have been able to learn interesting new } \\
\text { skills recently. }\end{array}$ & Same \\
\hline $\begin{array}{l}\text { 24. Most days I feel a sense of accomplishment } \\
\text { from what I do. }\end{array}$ & Same \\
\hline $\begin{array}{l}\text { 25. In my life I do not get much of a chance to } \\
\text { show how capable I am. }\end{array}$ & $\begin{array}{l}\text { In my life I do not get much of a chance to show } \\
\text { how capable I am at choosing television shows } \\
\text { online. }\end{array}$ \\
\hline 26. I often do not feel very capable. & $\begin{array}{l}\text { I often do not feel very capable at finding } \\
\text { television shows online that I enjoy. }\end{array}$ \\
\hline
\end{tabular}

27. What is your gender?

Male, Female, Other

28. What is your age?

29. What race do identify with?

Caucasian, African American, Native American, Hispanic, Pacifica Islander, I identify with more than one race (blank response), Other

30. What is the highest level of education you have completed?

Less than High school, High school, Some college, Technical college, Associates degree, Bachelor's degree, Master's degree, more than Master's degree

31. What is your marital status?

Married, single, divorced, widowed, separated

32 . What is your yearly income?

$0-20,000,20,001-40,000,40,001-60,000,60,001-80,000,80,001-100,000$, more than 100,001 


\section{Appendix B}

\section{Full list of top television programs}

The full list included: Big Bang Theory, The Voice, NCIS, American Idol, Modern

Family, How I Met Your Mother, Scandal, 2 Broke Girls, Grey’s Anatomy, Mike and

Molly, So you think you can dance?, New Girl, Castle, Simpsons, Dancing with the Stars, Criminal Minds, CSI, Elementary, Body of Proof, Family Guy, The Office, Daily Show with Jon Stewart, Law and Order SVU, American Dad, Burn Notice, Pawn Stars, Swamp People, Sullican \& Son, Graceland, Friends, Mountain Men, Eagleheart, Sponge Bob, House Hunters, Beyond Scared Straight, Intervention, George Lopez, King of the Hill, Sam \& Cat, Aqua Unit Patrol Squad 1, Seinfeld, Tabitha takes Over, Squidbillies, 16 Wishes, Bubble Guppies, Team Umizoomi, King of Queens, Property Wars, The Hero, Mickey Mouse Clubhouse, Chopped, Renovation Raiders, Chelsea Lately, Necessary Roughness, Bones, Conan, Supernatural, Fatal Encounters, Rehab Addict, and Charmed (tvbythenumbers.zap2it.com, 2013). 